\title{
0.1wt\% Boron addition Effect on dynamic compressive mechanical properties of Ti-6Al-4V alloy
}

\author{
Yang $\mathrm{Yu}^{1,2, *}$, Songxiao Hui ${ }^{1}$, Xujun $\mathrm{Mi}^{1}$, Wenjun $\mathrm{Ye}^{1}$, Qi Gao ${ }^{2}$ \\ ${ }^{1}$ State Key Lab of Nonferrous Metals \& Processes, General research institute for nonferrous \\ metals,Beijing, 10088 China \\ ${ }^{2}$ Institute of Baoti ,Baotai Group Ltd.co.,721014 China
}

\begin{abstract}
Boron addition effect on dynamic compression properties of Ti-6Al-4V (Ti-64A) alloy are investigated by Split Hopkinson Pressure Bar (SHPB). In the study, and relative damage mechanism is also analyzed. The results show that, as-cast microstructure is refined due to $0.1 \%$ Boron addition and also to lower the non-uniform distribution of strain, stress or local concentration due to inharmonic deformation. As well as both dynamic strain and average dynamic flow stress is improved with a reduction of the sensitivity of adiabatic shear behavior. As deformation microstructure loaded at high strain rate with $0.1 \mathrm{wt} \%$ boron addition, Dynamic strain and maximum absorbed energy is decrease $10 \% \sim 30 \%$ compare with Ti-64A alloy. Both Ti-64A and Ti-6Al-4V-0.1B (Ti-64B), average dynamic flow stress is close. At high speed impact load, it exhibits a damage of adiabatic shear and TiB phases bear loading during fracture. Adiabatic shear band is main reason of Ti-64A and Ti-64B alloys fracture failure through the deformed specimens' microstructure observation. Adiabatic shear band formation and expansion is a precursor of material shear fracture failure. Deformation cavity can be formation between TiB phase and matrix during the deformation process, but not the main reason of material fracture failure.
\end{abstract}

\section{Introduction}

Among the $\alpha+\beta$ titanium alloys, Ti-64A alloy is the most popular titanium alloy, widely used in the aerospace, power generation, chemical, and biomedical industries because of high specific particular strength and good corrosion resistance [1-3]. The alloy is usually served under high speed impact loading, and it is required to posse a good capacity to retain the integrity and continuity of their structure when loaded at high strain rates. Research shows that the dynamic compressive mechanical properties of Ti-64A alloy depend on the alloy composition, organizational status, composition and distribution of microscopic characteristics [4-8]. In addition to refined as-cast microstructure [9-14] also affects

* Corresponding author: yuyang@grinm.com 
dynamic performance by $0.1 \mathrm{wt} \%$ Boron addition. The present study is mainly devoted to understand $0.1 \mathrm{wt} \%$ Boron addition Effect on dynamic compressive mechanical properties of Ti-64A alloy with different microstructures.

\section{Materials and experiments}

Ti-64A and Ti-64B (nominal compositions) alloys were used in this study. Both ingots with $120 \mathrm{~mm}$ in diameter and $320 \mathrm{~mm}$ in length were produced by double vacuum arc remelting. The corresponding electrode was made by following Al-55V, and aluminumshot, and sponge titanium. Boron was added via master alloy Al-22Ti-7B. The ingots were forged and finally rolled in the $\beta$ phase field and $\alpha+\beta$ phase field. The as-cast microstructure specimens were directly used in this study without any treatments. Exquiaxed microstructure specimens were got by heattreatment at $750^{\circ} \mathrm{C}$ for 1 hour and aircooling. Bimodal microstructure specimens were treated the same fraction of $58 \%$ primary alpha phase by different heattreatment. Widmanstätten microstructures specimens were got by heattreatment above the transformation point temperature.

The dynamic loading experiments were carried out by the SHPB. The specimens with a size of $\phi 5 \mathrm{~mm} \times 5 \mathrm{~mm}$ are used in the SHPB experiments. The section headings are in boldface capital and lowercase letters. Second level headings are typed as part of the succeeding paragraph (like the subsection heading of this paragraph).

In order to subject the samples to higher strain rates, the dynamic loading was performed at room temperature on a modified SHPB system. It is an attractive device to investigate true stress-strain compression response of materials under high strain rates. It is particularly useful to determine mechanical properties of materials subjected to compression with high strain rates. Numerous other kinds of SHPB have been developed to perform bending, shear and torsion tests.

The SHPB device is based on one-dimensional elastic wave propagation theory. The strain, strain rate, and flow stress in the specimen is obtained from the measured values of the reflected wave amplitude and transmission wave amplitude by the following formulate.

$$
\begin{gathered}
\varepsilon \&=\frac{2 c_{b}}{L_{s}}\left(\varepsilon_{i}-\varepsilon_{t}\right) \\
\varepsilon=\int{ }_{0}^{t} \varepsilon \& d t \\
\sigma=\frac{A}{A_{s}} E \varepsilon_{t}
\end{gathered}
$$

where $C_{b}$ is the longitudinal-wave velocity in the incident and transmitted bars, $L$ is the effective gauge length of the specimen, $E$ is the Young's modulus of the incident and transmitted bars, and $A$ and $A_{s}$ are the cross-sectional areas of the bars and the specimen, respectively. In this study, the dynamic impact tests were performed at strain rates of above $3000 \mathrm{~s}^{-1}$ at room temperature.

\section{Result and Discussion}

\subsection{Effect of boron addition on dynamic stress-strain cure of Ti-64A alloy}

The true stress-strain curves of Ti-64A and Ti-64B alloy with different microstructures shows in Fig. 1. During dynamic loading process, the samples undergo elastic deformation, plastic deformation, and adiabatic shear localization. For the same microstructure after plastic deformation, flow stress remains stable with increasing strain rate. It means that the 
plastic flow stress is not sensitive to the microstructure and strain rate. However, the uniform plastic strain increases with increasing strain rate. The dynamic flow stress and uniform dynamic plastic strainof different microstructures are shown in Table 1. Specimens are failure after dynamic compression test. Uniform dynamic plastic strain which is the Strain between true stress does not change and decrease with the increase of strain. The dynamic flow stress is the average value of the flow stress in the uniform dynamic plastic strain.

The dynamic flow stress of as-cast microstructure is $1255 \mathrm{MPa}$ of Ti-64A alloy, which obviously lower than $1407 \mathrm{MPa}$ of Ti-64B. The uniform dynamic plastic strain of the former is 0.17 , while the latter is 0.22 . It is obviously that $0.1 \mathrm{wt} \%$ addition improved the dynamic properties of as-cast Ti-64A. $0.1 \%$ Boron addition and also to lower the non-uniform distribution of strain, stress or local concentration due to inharmonic deformation ${ }^{[14]}$. As well as both dynamic strain and average dynamic flow stress is improved with a reduction of the sensitivity of adiabatic shear behavior.

The dynamic flow stress of the exquiaxed microstructure is $1510 \mathrm{MPa}$ of Ti-64A alloy, which evidently higher than $1403 \mathrm{MPa}$ of Ti-64B. The uniform dynamic plastic strain of the former is 0.33 , while the latter is 0.24 . The dynamic flow stress of the bimodal microstructure is $1450 \mathrm{MPa}$ of Ti-64A alloy, which fairly approach to $1461 \mathrm{MPa}$ of Ti-64B. The uniform dynamic plastic strain of the former is 0.3 , while the latter is 0.27 . The dynamic flow stress of the Widmanstätten microstructure is $1500 \mathrm{MPa}$ of Ti-64A, which fairly approach to $1506 \mathrm{MPa}$ of Ti-64B. The uniform dynamic plastic strain of the former is 0.26 , while the latter is 0.18 . Both uniform dynamic plastic strain and dynamic flow stress of Ti-64A are higher than Ti-64B for the exquiaxed microstructure. For bimodal microstructure and Widmanstätten microstructure, The uniform dynamic plastic strain of Ti-64A is apparently higher than Ti-64B , while their dynamic flow stress are quite similar . It is apparently that $0.1 \mathrm{wt} \%$ addition reduces the dynamic properties of deformation microstructure of Ti-64A.
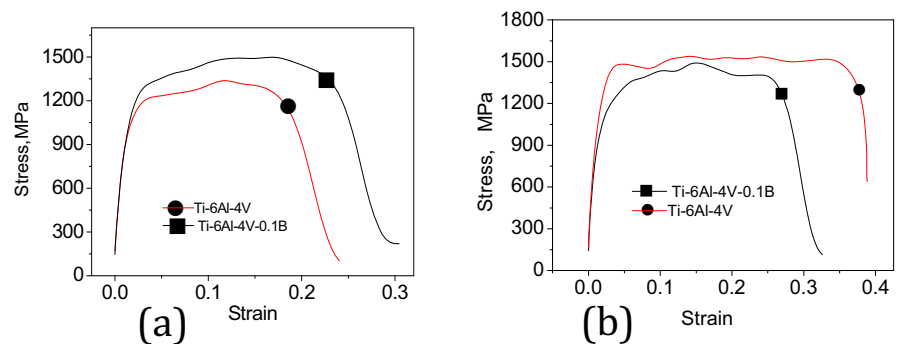

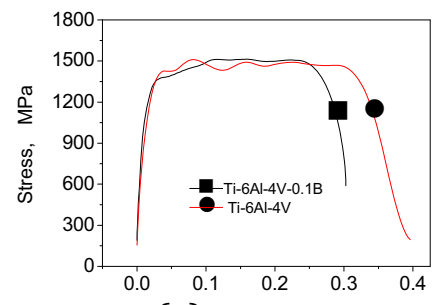

(c) Strain

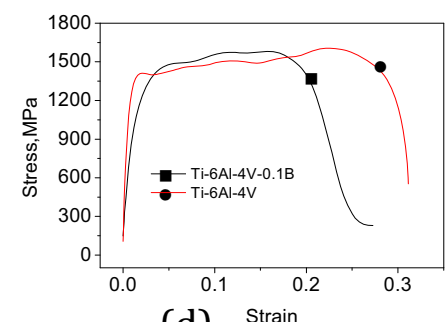

(d)

Fig.1 The dynamic true stress-strain curves of Ti-64A and Ti-64B alloy with different structure with strain rate. of more than $3000 \mathrm{~s}^{-1}$

(a)as-cast,(b) exquiaxed,(c)bimodal,(d) Widmanstätten 
Table.1 Dynamic Properties Of Ti-64a And Ti-64b Alloys

\begin{tabular}{|c|l|c|c|c|}
\hline \multirow{2}{*}{ Microstructure } & Alloy & Strain rate/ $\mathbf{s}^{-1}$ & $\begin{array}{c}\text { Uniform plastic } \\
\text { strain }\end{array}$ & Average stress/MPa \\
\hline \multirow{2}{*}{ As-cast } & Ti-64A & 3500 & 0.17 & 1255 \\
\cline { 2 - 5 } & Ti-64B & 3500 & 0.22 & 1407 \\
\hline \multirow{2}{*}{ Equiaxed } & Ti-64A & 4000 & 0.33 & 1510 \\
\cline { 2 - 5 } & Ti-64B & 3500 & 0.24 & 1403 \\
\hline \multirow{2}{*}{ Bimodal } & Ti-64A & 4000 & 0.3 & 1450 \\
\cline { 2 - 5 } & Ti-64B & 3100 & 0.27 & 1461 \\
\hline \multirow{2}{*}{ Nidmanstätten } & Ti-64A & 4000 & 0.26 & 1500 \\
\cline { 2 - 5 } & Ti-64B & 3500 & 0.18 & 1506 \\
\hline
\end{tabular}

\subsection{Effect of boron addition on maximum absorbed energy of Ti-64A alloy}

The absorbed energy during deformation is an important indicator to identify dynamic mechanical property. In the present, the impact absorbing energy is calculated as follows:

$$
E=\int_{\varepsilon s}^{\varepsilon f} \sigma \cdot \mathrm{d} \varepsilon
$$

wherein $\varepsilon_{\mathrm{s}}$ and $\varepsilon_{\mathrm{f}}$ are the starting point and ending point of plastic deformation. In order to seek for second derivative of the stress-strain curve yield stage and collapse stage, the corresponding strain is defined as es and ef at zero point. The maximum absorbed energy $(\mathrm{E})$ of different microstructures are shown in Fig. 2

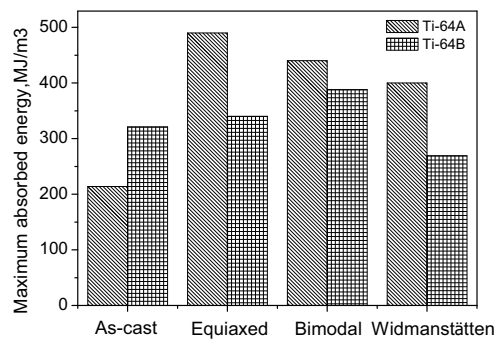

Fig.2 Maximum absorbed energy of Ti-64Ä and Ti-64B alloys

Fig.2 shows that the maximum absorbed energy of different microstructures. For maximum absorbed energy of as-cast microstructure is $321 \mathrm{MJ} / \mathrm{m}^{3}$ of Ti-64B before adiabatic shear failure, which is higher than $214 \mathrm{MJ} / \mathrm{m}^{3}$ of Ti-64A alloy. Equiaxed microstructure can reach $340 \mathrm{MJ} / \mathrm{m}^{3}$ of Ti- $64 \mathrm{~B}$, which is higher than $490 \mathrm{MJ} / \mathrm{m}^{3}$ of Ti-64A alloy. Bimodal microstructure is $388 \mathrm{MJ} / \mathrm{m}^{3}$ of Ti-64B, which is higher than $440 \mathrm{MJ} / \mathrm{m}^{3}$ of Ti-64A alloy. Widmanstätten microstructure is $269 \mathrm{MJ} / \mathrm{m}^{3}$ of Ti-64B, which is higher than $400 \mathrm{MJ} / \mathrm{m}^{3}$ of Ti-64A alloy. Using the maximum absorbed energy of one sample before shear failure to evaluate its adiabatic shearing sensitivity, an order of the sensitivity for different microstructures of Ti-64B alloy is bimodal microstructure $>$ exquiaxed microstructure $>$ as-cast microstructure $>$ Widmanstätten microstructure. $0.1 \mathrm{wt} \%$ Boron addition improved maximum absorbed energy of as-cast Ti-64A alloy, while reduced maximum absorbed energy of deformation microstructure. The order from strong to weak is Widmanstätten microstructure, exquiaxed microstructure, bimodal microstructure. 


\subsection{Deformed microstructure at high strain rate}

The bimodal microstructures are shown in Fig. 3 after loading at strain rate of above $3000 \mathrm{~s}^{-1}$. It can be seen that adiabatic shearing bands are formed in both the alloys. The adiabatic shearing is a phenomenon that a localized unstability is generally found in a material under an impact loading, having a close relation with failure behavior of a material [6]. Adiabatic shear band is main reason of Ti-64A and Ti-64B alloys fracture failure through the deformed specimens' microstructure observation. Adiabatic shear band formation and expansion is a precursor of material shear fracture failure.
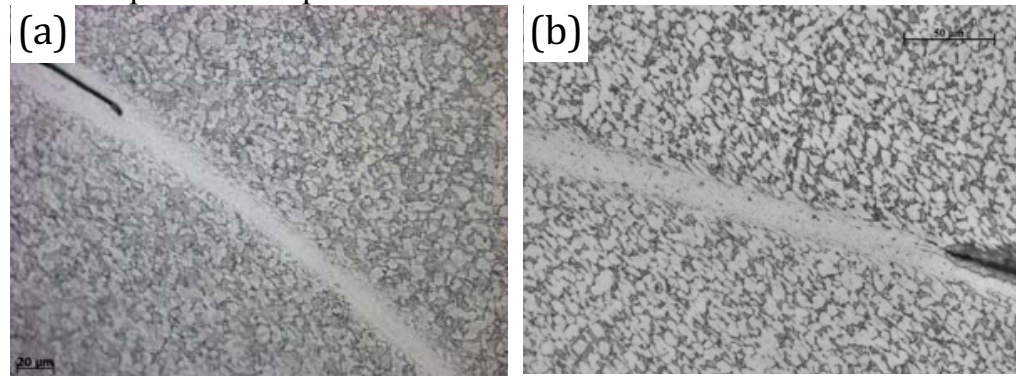

Fig.3 ASBs in (a) Ti-64A and (b) Ti-64B alloy of bimodal microstructure at strain rate above $3000 \mathrm{~s}^{-1}$

$\mathrm{TiB}$ in the matrix shows in Fig.4. It is obvious that TiB particles are torn or broken after deformation of dynamic compressive above $3000 \mathrm{~s}^{-1}$. In addition, caves appear at both the interface between $\mathrm{TiB}$ and the matrix and matrix due to the incompatible deformation. Cracks origin maybe appear in the matrix also interface between TiB and the matrix. Above all, The fracture failure of Ti-64B alloy may be related with TiB. The adiabatic shearing appears to have no direct relationship with the TiB.

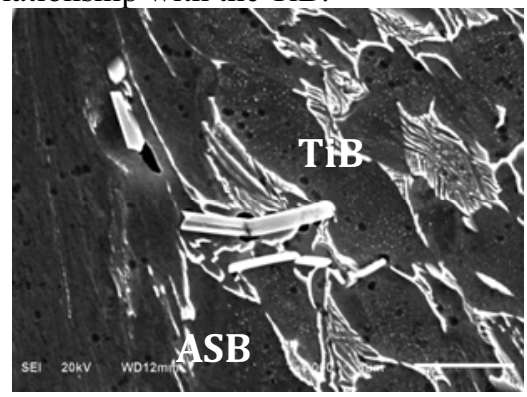

Fig.4 Deformation microstructure and fracture of Ti-64B under strain rate of above $3000 \mathrm{~s}^{-1}$ :

\section{Conclusions}

1) $0.1 \mathrm{wt} \%$ Boron addition evidently improved dynamic properties of as-cast Ti-64A alloy .

2) $0.1 \mathrm{wt} \%$ Boron addition reduced dynamic properties of Ti-64A alloy deformation microstructure. The order from strong to weak is Widmanstätten microstructure, exquiaxed microstructure, bimodal microstructure. 


\section{References}

1. Dalej.Mceldowney,Seshacharyulu Tamirisakandala and Daniel B.Miracle. Heat-treatment effects on the mircrostructure and tensile properties of powder metallurgy Ti-6Al-4V alloys modified with boron, Metallurgical and Materials Transactions A. April 2010 (41A) 1003-1015

2. Raghavan Srinivasan, Daniel Miracle, Sesh Tamirisakandala. Direct rolling of as-cast Ti-6Al-4V modified with trace additions of boron. Materials Science and Engineering A487 (2008) 541-551

3. Chandran, K.S.R. and D.B. Miracle, Titanium-Boron Alloys and Composites: Processing, Properties, and Applications. JOM, 2004(May) 32-41.

4. Lee D. G., Lee Y. H., Lee S., et al. Dynamic deformation behavior and ballistic impact properties of Ti-6Al-4V alloy having equiaxed and bimodal microstructures. Metallurgical and Materials Transactions A, 2004, 35(10) 3103-3112

5. Lee D. G., Kim Y. G., Nam D. H., et al. Dynamic deformation behavior and ballistic performance of Ti-6Al-4V alloy containing fine $\alpha 2$ (Ti3Al)precipitates. Materials Science and Engineering A, 2005, 391(1-2) 221-234

6. Liu Qinghua, Hui Songxiao, Ye Wenjun, Wang Guo, Hu Guangshan, Effect of the Content of Alloying Elements on Dynamic Mechanical Properties of TC4 Alloy,Rare Metal Materials and Engineering(In Chinese),2013(42) 1464-468

7. Yang Yu,Qi Gao,Xujun Mi, Songxiao Hui and Wenjun Ye, Deformation behavior of Ti-6Al-4V0.1B alloy loaded under high strain rates,Material Science Froum,2016(849) 266-270

8. Liu Qing-hua, Hui Song-xiao, Ye Wen-jun, Wang Guo, Hu Guang-shan, Effect of primary $\alpha$ phase content on dynamic stress-strain behavior of TC4 ELI titanium alloy, The Chinese Journal of Nonferrous Metals(In Chinese),2012(22) 2749-2755

9. Yamamoto, T. and A. Otsuki, Synthesis of Near Net Shape High Density TiB/Ti Composite. Materials Science and Engineering A, 1997. 239-240 647-651.

10. Indrani Sen, S. Tamirisakandala , D.B. Miracle , U. Ramamurty , Microstructural effects on the mechanical behavior of B-modified Ti-6Al-4V alloys, Acta Materialia 55 (2007) 4983-4993

11. O.O. Bilous, L.V. Artyukh, A.A. Bondar, T.Ya. Velikanova, M.P. Burka,M.P. Brodnikovskyi, O.S. Fomichov, N.I. Tsyganenko, S.O. Firstov, Effect of boron on the structure and mechanical properties of Ti-6Al and Ti-6Al-4V[J], Materials Science and Engineering A 2005(402) 76-83

12. Yang Yu, Songxiao Hui, Wenjun Ye, et al. Study on Hot deformation behavior of Ti-6Al-4V-0.1B alloy with equiaxed Microstructure .Advanced Materials Research,2012, 428 185-189.

13. Yu Y., Xiong B. Q., Hui S. X., et al. Hot Deformation Behavior and Globularization Mechanism of Ti-6Al-4V-0.1B Alloy with Lamellar Microstructure. Rare metals.April 2013,32(2) 122-128

14. Yu Yang, Li Chenglin, Ye Wenjun and Hui Songxiao, Effect of trace boron addition on microstructure and properties of as-cast Ti-6Al-4V alloy, Rare Metal Materials and Engineering,2014,43(12) 2908-2911 